\title{
Association of perioperative hyperglycemic state with postoperative infection
}

\author{
J P Ghildiyal', Archna Ghildiyal' ${ }^{2}$, Sarsij Sharma ${ }^{3}$, Bushra lqbal', Shraddha Singh ${ }^{5}$ \\ ${ }^{1}$ Professor, Department of Surgery, Hind Institute of Medical Sciences, Ataria, Sitapur, ${ }^{2}$ Associate Professor, ${ }^{4}$ Ph.D. \\ Student, ${ }^{5}$ Professor, Department of Physiology, King George Medical University, Lucknow, Uttar Pradesh, ${ }^{3}$ Senior \\ Resident, Department of Plastic Surgery, Safdarjung Hospital, New Delhi, India
}

Background: Perioperative hyperglycemia is frequently encountered in clinical practice. Recent evidence suggests that hyperglycemia plays a significant role in the development of post-operative infections (POI). Major focus has been placed on whether hyperglycemia, as an independent risk factor, is associated with increased infection. The optimal targeted blood glucose range to prevent POI remains unclear, especially in the intra-operative period. Aims and Objective: To study the association between perioperative hyperglycemia to the subsequent risk of post-operative infections through a prospective observational study. Materials and Methods: A prospective study of 101 patients undergoing different types of general surgery procedures followed upto 30 days post-operatively was done. Random Blood Sugar (RBS) was taken (1) Pre-operatively (2) Intra-operatively (3) Postoperatively- after 6, 24 and 48 hours. Primary end points of the study were (1) Surgical wound infection (2) Urinary tract infection (3) Septicemia. Results: Out of 101 patients, 57 developed perioperative hyperglycemia (incidence - 56.4\%). In normoglycemic group of patients, infection rate was $4.5 \%(2 / 44)$ as compared to $26.3 \%(15 / 57)$ in perioperative hyperglycemic group. Conclusion: The present study provides a convincing evidence of an association between perioperative hyperglycemia and post-operative infection apart from giving a possible relationship between preoperative blood sugar levels and post-operative infection.

Key words: Perioperative, Hyperglycemia, Infection, Post-operative
http://nepjol.info/index.php/AJMS DOI: 10.3126/ajms.v7i6.15336 E-ISSN: 2091-0576 P-ISSN: $2467-9100$

\section{INTRODUCTION}

Post-operative infections (POI) including surgical site infections (SSI) are the common nosocomial infections and leads to various surgical complications. ${ }^{1-5}$ In India, the healthcare expenses are usually a burden to the family. The addition of cost associated with post-operative infections/ complications represents a significant saddle to patient and hospital. Preoperative screening of plasma glucose may be able to identify the risk of infection following surgery. On the other hand, perioperative hyperglycemia increases the risk of post-operative infections ${ }^{6}$ and other complications $s^{7,8}$ in surgery patients. It has been reported that incidence of post-operative wound infections varies between $5 \%$ and $25 \% .{ }^{9,10}$ Various factors reported to be associated with postoperative infection after surgery includes body mass index (BMI), ${ }^{11}$ gender, age, chronic use of steroidal drug ${ }^{12}$ and hyperglycemia. ${ }^{13,14}$ Post-operative hyperglycemia, one of the common risk factor, can easily be modified instead of other potential risk factors for post-operative infections. Persistent hyperglycemia is associated with diminished bactericidal activity, ${ }^{15}$ impairment of phagocytosis, decreased release of lysosomal enzymes, ${ }^{16}$ and reduced production of reactive oxygen species ${ }^{17,18}$ by neutrophils. It is hypothesized that the abnormal leukocyte function in hyperglycemia condition may be due to a down-regulation of adhesion molecules that regulate leukocyte recruitment during the course of inflammatory processes. ${ }^{19}$ Leucocytes deficiencies appear to improve in well control of hyperglycemia. Now, it becomes clear that tight glycaemic control should improve the clinical outcome for all surgical patients. Hyperglycemia induced by stress including surgical stress, trauma and critical illness resulting in worse surgical outcome independent of diabetic 
status of the patient..$^{20,21}$ In recent days, there has been increased interest in post-operative glucose metabolism and complications after surgery, both in patients with and without diabetes mellitus. ${ }^{22}$ The association between perioperative blood glucose and the incidence of post-operative infections stays indistinct in the majority of surgical patients. The present study designed to prove the association between perioperative hyperglycemia and subsequent risk of postoperative bacterial infections.

\section{MATERIAL AND METHODS}

The study was conducted at Era's Lucknow Medical College and Hospital during the period of six months. The study was approved by the institutional ethics committee and informed consent was taken prior to study. A total of 101 patients (who enrolled for elective surgery as their treatment) were included in this study. Patients who were immunocompromised or taking steroids were excluded from the study. On the basis of perioperative Random Blood Sugar (PORBS), patients were divided in two groups: patient with Random Blood Sugar less than $140 \mathrm{mg} / \mathrm{dl}$ were placed in Group-I $(\mathrm{n}=44)$ (normoglycemic) and those with PORBS more than $140 \mathrm{mg} / \mathrm{dl}$ recognized as Group-II ( $\mathrm{n}=57$ ) (hyperglycemic). Age, sex, height and weight were recorded as per standard protocol. Random Blood Sugar (RBS) was estimated at preoperative, intraoperative and post-operative stages. In post-operative stages, RBS was estimated at $6^{\text {th }}, 24^{\text {th }}$ and $48^{\text {th }}$ hour after surgery. The entire patients were followed for 30 days after surgery. The post-operative infection (primary outcome of the study) was assessed by wound infection, urinary tract infections and septicemia. RBS was measured by Glucometer. The statistical analysis was done using SPSS (statistical package for social sciences) version 15.0 statistical parameters. The values were represented by mean and $+\mathrm{SD}$.

\section{RESULTS}

The study sample had 101 patients including 64 males and 37 females. The average age (years) of normoglycemic and hyperglycemic group showed no significant difference and it was $39.95+15.12$ and $41.09+12.60$ respectively. Our data showed that the difference of PORBS in group-I
(102.50 mg/dl + 40.40) and group-II (131.11 mg/dl + 60.60) was statistically significant $(p<0.005)$ (Table 1$)$. Various types of operative procedures were adopted including exploratory laprotomy (32.7\%); open cholecystectomy $(12.9 \%)$ followed by laparoscopic cholecystectomy $(11.9 \%)$; hernioplast ( $8 \%)$; pyelolethotomy $(7.9 \%)$ and others $(26.6$ percent) (Table 2). Our data suggests that the PORBS rises from $102.5 \mathrm{mg} / \mathrm{dl}+40.40$ to $118.50 \mathrm{mg} / \mathrm{dl}+26.40$ in Group -I during intra operative stage. This increment in intra operative Random Blood Sugar (IORBS) was more in group -II and the post-operative Random Blood Sugar also followed the same pattern. The post-operative blood sugar levels remain high till $48^{\text {th }}$ hour following surgery (Table 1). It was also observed that the post-operative infections were only $4.5 \%$ in normoglycemic group while it was more prevalent $(26.3 \%$ ) in hyperglycemic group (Table 3$)$. The primary outcome measure includes wound dehiscence and positive urine culture were the most common $(n=8,8.9 \%$ each) source of infections detected in the study. There were $5.9 \%$ cases with detection of infections through surgical, wounds culture and equal number of subjects with total leucocytes count $>11000$ cells $/ \mathrm{mm}^{3}$ (Table 4).

\section{DISCUSSION}

Post-operative infections are common and often a costly surgical complication. Perioperative hyperglycemia in critically ill surgery patients increases the risk of postoperative infections ${ }^{6}$ and improved control of blood glucose fluxes has been shown to improve survival and decrease morbidity. ${ }^{20,21}$ Despite large number of operations performed, a clear association between perioperative blood glucose control and post-operative complications remains ill-defined for the majority of surgery patients.

In the wake of convincing indications of a possible relationship between perioperative hyperglycemia and subsequent risk of post-operative infections, the present prospective observational study was carried out to examine this relationship in our set up and to study the effect of perioperative hyperglycemia on post-operative bacterial infections. A total of 101 patients were enrolled in the present study. Out of these, 57(56.4\%) developed perioperative

\section{Table 1: Distribution of random blood sugar in various groups}

\begin{tabular}{|c|c|c|c|c|c|c|c|}
\hline \multirow[t]{2}{*}{ S. No } & \multirow[t]{2}{*}{ Blood sugar levels (mg/dl) } & \multicolumn{2}{|c|}{ Group-I (n=44) } & \multicolumn{2}{|c|}{ Group-II (n=57) } & \multicolumn{2}{|c|}{ Significance } \\
\hline & & Mean & +SD & Mean & +SD & $t$ value & $p$ value \\
\hline 1 & Preoperative & 102.50 & 40.40 & 131.11 & 60.60 & -2.752 & 0.007 \\
\hline 2 & Intraoperative & 118.50 & 26.40 & 212.50 & 59.20 & -1.0138 & $<0.001$ \\
\hline 3 & 6 hrs post-op & 132.70 & 27.70 & 195.00 & 69.00 & -5.846 & $<0.001$ \\
\hline 4 & 24 hrs post-op & 127.30 & 27.20 & 186.00 & 51.00 & -7.213 & $<0.001$ \\
\hline 5 & 48 hrs post-op & 129.10 & 29.70 & 173.00 & 51.70 & -5.193 & $<0.001$ \\
\hline
\end{tabular}




\begin{tabular}{llcc}
\multicolumn{4}{l}{ Table 2: Types of operative procedure } \\
\hline S. No & Procedures & No. & Percentage \\
\hline 1 & Appendectomy & 4 & 4.0 \\
2 & Choledocholithotomy & 3 & 3.0 \\
3 & Epigastric Hernioplasty & 1 & 1.0 \\
4 & Exploratory Laparotomy & 33 & 32.7 \\
5 & Haemorrhoidectomy & 1 & 1.0 \\
6 & Hemicolectomy & 1 & 10 \\
7 & Hernioplasty & 9 & 8.9 \\
8 & Herniorraphy & 2 & 2.0 \\
9 & Herniorrhaphy with Eversion & 2 & 2.0 \\
& of Sac & 3 & 3.0 \\
10 & Ileostomy Closure & 12 & 11.9 \\
11 & Laproscopic Cholecystectomy & 2 & 2.0 \\
12 & Lumbar Sympathectomy & 3 & 3.0 \\
13 & Modified Radical & & \\
& Mastetctomy & 1 & 1.0 \\
14 & Nephrolithotomy & 13 & 12.9 \\
15 & Open Cholecystectomy & 1 & 1.0 \\
16 & Open Cholecystectomy with & & \\
& Epigastric Hernioplasty & 1 & 1.0 \\
17 & Orchidopexy & 8 & 7.9 \\
18 & Pyelolithotomy & 1 & 1.0 \\
19 & Reduction Mammoplasty & &
\end{tabular}

\begin{tabular}{|c|c|c|c|c|c|}
\hline \multirow[t]{2}{*}{ S. No } & \multirow[t]{2}{*}{ Infections } & \multicolumn{2}{|c|}{ Group-I $(n=44)$} & \multicolumn{2}{|c|}{ Group-II $(n=57)$} \\
\hline & & Number & $\%$ & Number & $\%$ \\
\hline 1 & No & 42 & 95.5 & 42 & 73.3 \\
\hline 2 & Yes & 2 & 4.5 & 15 & 26.3 \\
\hline
\end{tabular}

\begin{tabular}{|c|c|c|c|}
\hline S. No & Outcomes & Number & Patient \\
\hline 1 & Wound dehiscence & 9 & 8.9 \\
\hline 2 & Urine culture & 9 & 8.9 \\
\hline 3 & Blood culture & 0 & 0 \\
\hline 4 & Surgical wound culture & 6 & 5.9 \\
\hline 5 & $\mathrm{TLC}>11000$ cells $/ \mathrm{mm}^{3}$ & 6 & 5.9 \\
\hline
\end{tabular}

hyperglycemia. The incidence of perioperative hyperglycemia has been reported to be varying in different studies covering different types of surgeries in different groups of patients. The incidence of hyperglycemia might vary in different types of subjects, different procedures and different level of glycemic control. The glycemic control is considered to be of poor level among Indians and Asians ${ }^{23}$ and thus the incidence of hyperglycemia might be of higher order in our subjects.

In present study, perioperative hyperglycemia was found to be significantly associated with the post-operative infection. The incidence of infection among hyperglycemics was observed to be $26.3 \%$ as compared to $4.5 \%$ among nonhyperglycemics. A number of studies have supported the finding that post-operative infection rate is significantly higher among patients developing perioperative hyperglycemia. The findings in present study are close to the study which states that an incidence of post-operative infection to the tune of $24.6 \%$ among hyperglycemics as compared to $4.25 \%$ among normoglycemics. ${ }^{24}$ In present study, we have found that the incidence of infection among those with perioperative hyperglycemia was 5.8 times higher (15/57 vs $2 / 44)$.

Previous findings state that glucose levels among patients having higher proportions of hyperglycemia were significantly high as compared to those with lower proportion of hyperglycemia. Thus, it has a relationship with preoperative blood sugar level itself and high preoperative sugar level might increase risk of hyperglycemia in the intra and post-operative period. ${ }^{25}$ In present study, we find that the mean blood sugar levels were increase significantly in Group II (patients with perioperative hyperglycemia).

In present study perioperative hyperglycemia was found to be significantly associated with the post-operative infection. The findings in present study are close to the findings of study which states that incidence of post-operative infection to the tune of $24.6 \%$ among hyperglycemics as compared to $4.25 \%$ among normoglycemics. ${ }^{24}$

In non diabetic, subjects were three times more likely to develop the infection if their morning blood glucose was $>140 \mathrm{mg} / \mathrm{dl}$ on post-operative day $1 .{ }^{26} \mathrm{In}$ present study a total of 10 out of 29 patients who developed post-operative hyperglycemia developed infection, thereby showing the incidence of infection to be around 3.5 times higher as compared to others.

In present study we had made an attempt to associate the perioperative blood sugar levels with post-operative infections. As indicated above, we had observed a significant association of perioperative blood sugar levels with intra and post-operative hyperglycemia. This relationship prompts us to seek an association between preoperative blood sugar level and infection, irrespective of their hyperglycemic and normoglycemic condition. For this purpose, four quartile of baseline blood sugar levels were assessed for subsequent post-operative infection. Diabetic patient undergoes coronary artery bypass surgery; preoperative hyperglycemia is an independent predictor of short-term infectious complications. ${ }^{27}$ Our findings are very significant from the point of view of a possible utility of perioperative blood sugar levels (not hyperglycemic strata alone) as a predictor of postoperative infection especially among non-diabetic patients.

\section{CONCLUSION}

The findings in present study provide a convincing evidence that perioperative hyperglycemia increases the risk of post-operative infection. However, the findings must be 
interpreted cautiously as a very low perioperative blood sugar level might reduce the risk of infection but pose other complications related to hypoglycemia leading to serious consequences, including death. Considering the easy feasibility of assessment, we recommend that a pool of large data should be created by carrying out more studies for different surgical procedures so that more convincing and powerful evidence in support may be gathered.

\section{ACKNOWLEDGEMENT}

I am sincerely thankful to Prof. Pradeep Kumar, Department of Physiology for his contribution in data management and statistical analysis.

\section{REFERENCES}

1. Nichols RL: Preventing surgical site infections: a surgeon's perspective. Emerg Infect Dis 2001; 7: 220-224.

2. Anderson DJ, Sexton DJ, Kanafani ZA, Auten G and Kaye KS Severe surgical site infection in community hospitals: Epidemiology, key procedures and the changing prevalence of methicillin-resistant Staphylococcus aureus. Infect Control Hosp Epidemiol 2007; 28: 1047-1053.

3. Graves EJ. National Hospital Discharge Survey: Annual Summary, 1987. Hyattsville, MD: Department of Health and Human Services Publication (PHS) 89-1760; 1989. National Center for Health Statistics. Series 13, no. 99.

4. National Nosocomial Infections Surveillance (NNIS) System Report, data summary from January 1992 through June 2004, issued October 2004. Am J Infect Control 2004; 32: 470-485.

5. Mangram AJ, Horan TC, Pearson ML, Silver LC and Jarvis WR. Guideline for prevention of surgical site infection, 1999. Hospital Infection Control Practices Advisory Committee. Infect Control Hosp Epidemiol 1999; 20: 250-278.

6. Ambiru S, Kato A, Kimura F, Shimizu H, Yoshidome H, Otsuka M, et al. Poor post-operative blood glucose control increases surgical site infections after surgery for hepato-biliarypancreatic cancer: a prospective study in a high-volume institute in Japan. J Hosp Infect 2008; 68: 230-233.

7. Gale SC, Sicoutris C, Reilly PM, Schwab CW and Gracias VH. Poor glycemic control is associated with increased mortality in critically ill trauma patients. Am Surg 2007; 73: 454-460.

8. Whitcomb BW, Pradhan EK, Pittas AG, Roghmann MC and Perencevich EN. Impact of admission hyperglycemia on hospital mortality in various intensive care unit populations. Crit Care Med 2005; 33(12):2772-2777.

9. Kent KC, Bartek S, Kuntz KM, Anninos E and Skillman JJ. Prospective study of wound complications in continuous infrainguinal incisions after lower limb arterial reconstruction: incidence, risk factors and cost. Surgery 1996; 119(4): 378-383.

10. Schepers A, Klinkert P, Vrancken Peeters MP and Breslau PJ. Complication registration in patients after peripheral arterial bypass surgery. Ann Vasc Surg 2003; 17(2): 198-202.
11. Dima Y, Abdallah, Mutaz M., Jadaan and John P McCabe. Body mass index and risk of surgical site infection following spine surgery: a meta-analysis. Eur Spine J 2013; 22(12): 2800-2809.

12. Sebastian A, Huddleston $P$, Kakar S, Habermann E, Wagie A and Nassr A. Risk factors for surgical site infection after posterior cervical spine surgery: An analysis of 5,441 patients from the ACS NSQIP 2005-2012. Spine J 2016; 16(4):504-509.

13. Hruska LA, Smith JM, Hendy MP, Fritz VL and McAdams S. Continuous insulin infusion reduces infectious complications in diabetics following coronary surgery. J Card Surg 2005; 20(5): 403-407.

14. Shah BR and Hux JE. Quantifying the risk of infectious diseases for people with diabetes. Diabetes Care 2003; 26(2): 510-513.

15. Rayfield EJ, Ault MJ, Keusch GT, Brothers MJ, Nechemias C and Smith $\mathrm{H}$. Infection and diabetes: The case for glucose control. Am J Med 1982; 72: 439-450.

16. Bagdade JD, Nielson KL and Bulger RJ. Reversible abnormalities in phagocytic function in poorly controlled diabetic patients. Am J Med Sci 1972; 263: 451-456.

17. Nielson CP and Hindson DA. Inhibition of polymorphonuclear leukocyte respiratory burst by elevated glucose concentrations in vitro. Diabetes 1989; 38: 1031-1035.

18. Jakelic J, Kokic S, Hozo I, Maras J and Fabijanic D. Nonspecific immunity in diabetes: hyperglycemia decreases phagocytic activity of leukocytes in diabetic patients. Med Arh 1995; 49: 9-12.

19. Argenbright $L W$, Letts $L G$ and Rothlein R. Monoclonal antibodies to the leukocyte membrane CD18 glycoprotein complex and to intercellular adhesion molecule-1 inhibits leukocyte-endothelial adhesion in rabbits. J Leukoc Biol 1991; 49: 253-257.

20. Van den Berghe G, Wouters P, Weekers F, Verwaest C, Bruyninckx $F$, Schetz $M$, et al. Intensive insulin therapy in critically ill patients. Engl J Med 2001; 345(19): 1359-1364.

21. Van den Berghe G, Wilmer A, Hermans G, Meersseman W, Pieter J, Wouters PJ, et al. Intensive insulin therapy in the medical ICU. Engl J Med 2006; 354(5): 449-461.

22. Vriesendorp TM, Morélis QJ, DeVries JH, Legemate DA and Hoekstra JBL. Early post-operative Glucose Levels are an Independent Risk Factor for Infection after Peripheral Vascular Surgery. A Retrospective Study. EJVES 2004; 28(5): 520-525.

23. Ramachandran $A$, Chamukuttan $S$, Immaneni $S$, Shanmugam RM, Vishnu N, Viswanathan V, et al, High Incidence of Glucose Intolerance in Asian-Indian Subjects With Acute Coronary Syndrome. Diabetes Care 2005; 28(10): 2492-2496.

24. Pomposelli JJ, Baxter JK $3^{\text {rd }}$, Babineau TJ, Pomfret EA, Driscoll DF, Forse RA, et al. Early post-operative glucose control predicts nosocomial infection rate in diabetic patients. J Parenter Entera Nutr [Whole Parenter J Nutr] 1998; 22: 77-81. Spanish

25. Estrada CA, Young JA, Nifong LW and Chitwood WR. Outcomes and perioperative hyperglycemia in patients with or without diabetes mellitus undergoing coronary artery bypass grafting. Ann Thorac Surg 2003; 75: 1392-1399.

26. Mraovic B, Suh D and Parvizi J. Perioperative Hyperglycemia and Post-operative Infection after Lower Limb Arthroplasty. Journal of Diabetes Science and Technology 2011; 5(2): 412-418.

27. Guvener M, Pasaoglu I, Demircin M and Oc M. Perioperative hyperglycemia is a strong correlate of post-operative infection in type II diabetic patients after coronary artery bypass grafting. Endocr J 2002; 49(5): 531-537.

\section{Authors Contribution:}

JPG and AG - Supervised the experimental work of the study, manuscript preparation and critical revision of the manuscript; SS - Collected the samples and carried out all the experimental work; BI - Contributed in conceptualized study, literature search and statistically analysed the data; SS - Helped in statistical analysis, data interpretation and finalizing the manuscript.

Source of Support: Nil, Conflict of Interest: None declared. 